\title{
Servant Leadership and Spirituality Among Undergraduate and Graduate Nursing Students
}

\author{
Joyce L. Maglione ${ }^{1}$ (D) Kathleen Neville ${ }^{1}$
}

Accepted: 10 June 2021 / Published online: 20 June 2021

(C) The Author(s), under exclusive licence to Springer Science+Business Media, LLC, part of Springer Nature 2021

\begin{abstract}
Nursing students represent the future of nursing. In today's increasingly complex health care environment nurse leaders must develop a distinct leadership style based on methodologically sound research to shape tomorrow's clinical practice. The purpose of this study is to determine the relationship between spirituality and servant leadership characteristics in undergraduate and graduate nursing students. Although the relationship between these two concepts has been studied in the workplace, less is known about the links of servant leadership and spirituality among nursing students. Data from 66 student participants were analyzed using the Servant Leadership and Spirituality Scales. The results indicated nursing students had relatively high levels of spirituality and servant leadership. A significant positive association was found between overall servant leadership and spirituality scores. Servant leadership characteristics increased from Bachelor of Science in Nursing (BSN) to Master of Science in Nursing (MSN) program students, but then decreased among the doctoral students. A decline in servant leadership was also demonstrated in nurses in practice greater than 10 years. Spirituality scores declined slightly in nurses' early years of practice, then rebounded and continued to progress with increased years of practice. The authors concluded that students that select nursing as a professional career may inherently possess characteristics of servant leadership and spirituality.
\end{abstract}

Keywords Servant leadership $\cdot$ Spirituality $\cdot$ Nursing students

Joyce L. Maglione

Joyce.Maglione@shu.edu

1 College of Nursing, Seton Hall University, Interprofessional Health Sciences Campus, 123

Metro Boulevard, Suite S-3114, Nutley, NJ 07110, USA 


\section{Introduction}

Nursing students represent the future of nursing. In today's increasingly complex health care environment nurse leaders must develop a distinct leadership style based on methodologically sound research to shape tomorrow's clinical practice. Recent research has strongly supported the servant leadership style as the most appropriate form of leadership for nursing (O'Brien, 2014). Servant leadership is a style whereby the leader is first a servant, to serve others. The servant-leader shares knowledge and power by placing the needs of others first and creating an environment for followers' growth. Nurse leaders may find themselves in situations to set aside their self-interest for the betterment of their followers. The education of this leadership style is essential for nursing students, our future nurse leaders, as they embark on a career grounded in nursing's tradition as a vocation serving the needs of the sick, vulnerable, and disadvantaged.

As the research on servant leadership has expanded, there is a growing interest to understand the relationship between servant leadership and spirituality. Although there is a lack of consensus on the definitions of both servant leadership and spirituality, scholars have identified several similarities between the two concepts and their importance in the workplace. Ashmos and Duchon (2000) conceptualized workplace spirituality as "the recognition that employees have an inner life that nourishes and is nourished by meaningful work that takes place in the context of community" (p. 137). In an article on "spirituality at workplace" Reddy (2019) determined that servant-led organizations produce a spiritual culture that creates a caring institution. He concluded that "the inclusion of (sic) spiritual element into the workplace through the perspective of serving others makes servant leadership a successful driving force for spirituality at workplace" (p. 12). Khan et al. (2015) also studied the impact of servant leadership on workplace spirituality and found that the motivating influence of servant-leaders enhanced workplace spirituality that resulted in a more meaningful workplace for followers.

The existing literature demonstrates a synergistic relationship between servant leadership and various dimensions of spirituality (Khan et al., 2015). Although the relationship between these two concepts has been studied in the workplace, less is known about the links of servant leadership and spirituality among university nursing students. To address this gap, the purpose of this study is to examine the relationship between the characteristics of servant leadership and spirituality in nursing students in baccalaureate and graduate programs.

\section{Literature Review}

\section{Servant Leadership}

The concept of servant leadership has existed since Biblical times exemplified by the life of Jesus of Nazareth. While many authors and theologians have written about servant leadership, Robert Greenleaf has written extensively about servant 
leadership and management research following his career at American Telephone and Telegraph (AT\&T). Sensing that a leadership crisis existed, the idea of servant leadership came to Greenleaf after reading Herman Hesse's The Journey to the East (2003). This is the story of a band of men each with their own reasons to embark on a spiritual journey where the exact purpose and destination is not apparent. The main character Leo is tasked with doing the menial chores of a servant. With his aptitude for inspirational song and positive spirit, Leo is the glue that holds the group together providing confidence and direction. When Leo disappears, group cohesion vanishes, and the group abandons its journey. Years later the story's narrator discovers that Leo who all thought was a servant was the head of the order that sponsored the journey. First being known as a servant to others demonstrated Leo's greatness as a leader. The insightfulness of this tale gave birth to Greenleaf's philosophy of servant leadership, to lead is to serve (Greenleaf, 2002).

Focusing on moral behaviors, servant leadership presents an ethical perspective of leadership where service is rooted in the leader-follower relationship. Although it is paradoxical to consider a leader as a servant, servant-leaders are driven by the motivation to serve others. Servant-leaders nurture, foster, and empower followers so that they may flourish. Servant-leaders want to serve before they want to lead. This approach differs with leaders that lead first who may be motivated by the need to secure power (Greenleaf, 2002). Since Greenleaf's original work, many scholars have attempted to clearly define the characteristics of servant leadership. Although others have added to the body of servant leadership literature that addresses the attributes of the concept (Liden et al., 2008; Sipe \& Frick, 2009), Spears' (2010) classic work that identified ten characteristics critical to the development of servant leadership is considered "the most respected and referred to list of servant leadership characteristics" (Focht \& Ponton, 2015, p. 45). These characteristics are as follows: listening, empathy, healing, awareness, persuasion, conceptualization, foresight, stewardship, commitment to growth, and building community.

Research findings suggest that individuals who practice servant leadership principles within organizations are more effective (Jafai et al., 2016). Baykal et al. (2018) found working in a servant-leader work environment contributed to positive feelings of gratitude and empowerment that affected performance. Additional research completed in the organizational setting demonstrated a positive relationship between servant leadership and knowledge sharing, thriving at work, and employee creativity (Sheikh et al., 2019), job satisfaction (Farrington \& Lillah, 2018), and job performance (Schwarz et al., 2016).

\section{Spirituality}

Spirituality in leadership has been explained as a model that incorporates altruistic love, hope and faith. According to Nelms et al. (2007), spirituality is conceptually defined as a belief system that acknowledges the presence of God, Creator, or Higher Power, contributing to a more meaningful life and adds to an individual's well-being. The significance of spirituality as it relates to nurses was evident through the actions of Florence Nightingale, the founder of modern nursing. Her spirituality 
in caring for the sick is reflected in her original writings and teaching (Nightingale, 1860). More recently, spirituality is represented in several well-established nursing theories where spirituality contributes to the multidimensional holistic view of the health and well-being of individuals. Watson, Roy, and Neuman are among several nursing theorists that address the patient's spirituality (Masters, 2015). Spirituality is also highlighted in the practice of holistic nursing. According to the American Holistic Nursing Association (AHNA) (2020), holistic nursing recognizes the physical, mental, emotional, spiritual, and environmental condition when assessing a patient's health beliefs and experiences.

In a study of graduate nursing students, Robinson (2015) found that nurses' spirituality was professionally and personally empowering and patients had positive outcomes when spiritual care was delivered. In a multinational study of nurse practitioners, DeConinck et al. (2016) found that nurse practitioners that considered spirituality to be important were more likely to deliver spiritual care to their patients. Spiritual care refers to assessing and responding to the spiritual and religious concerns of patients and families (Hospice and Palliative Nurses Association, 2015).

Several studies demonstrate the positive effects of spirituality for nurse leaders such as self-esteem (Ozawa et al., 2017), ethical behavior (Naseer et al., 2020), motivation and job satisfaction (Rahmati et al., 2018), and resiliency (Almazon et al., 2018). Spirituality is also considered to decrease nurse burnout (Wu et al., 2020) and improve quality of life (Roming and Howard, 2019).

\section{Methodology}

After receiving approval from the university's institutional review board this study was conducted in a faith-based liberal arts university in the northeastern USA. The purposive convenience sample included 66 undergraduate and graduate nursing students enrolled in the university. Data collection was over a 3-month period at the end of the academic year in 2020 .

After informed consent was obtained students completed a demographic data questionnaire, the Servant Leadership Scale (Association of Catholic Colleges and Universities [ACCU], nd), and the Spirituality Scale (Nelms et al., 2007). The demographic questionnaire consisted of the participant's age, gender, ethnicity, nursing degree program they were enrolled in, year of study in their program, years of experience employed in health care, and if they participated in any volunteer experiences within the past 3 years that was not required by an academic program. The 24-item Servant Leadership Scale encompassed the following eight dimensions: empowering others defined as looking for the potential in all people and seeking to encourage and support others' positive growth; humility is considered being without pretense or arrogance, admitting and accepting one's flaws, and placing oneself above no one; stewardship is seeking to create the greatest good for others and using resources for the greatest benefit of the community; communication is defined as listening to the needs of others and the community in order to develop a deep understanding of how to work together to meet those needs; social justice is acting on behalf of the poor, and advocating for justice issues; cultural leadership is defined as advocating for 


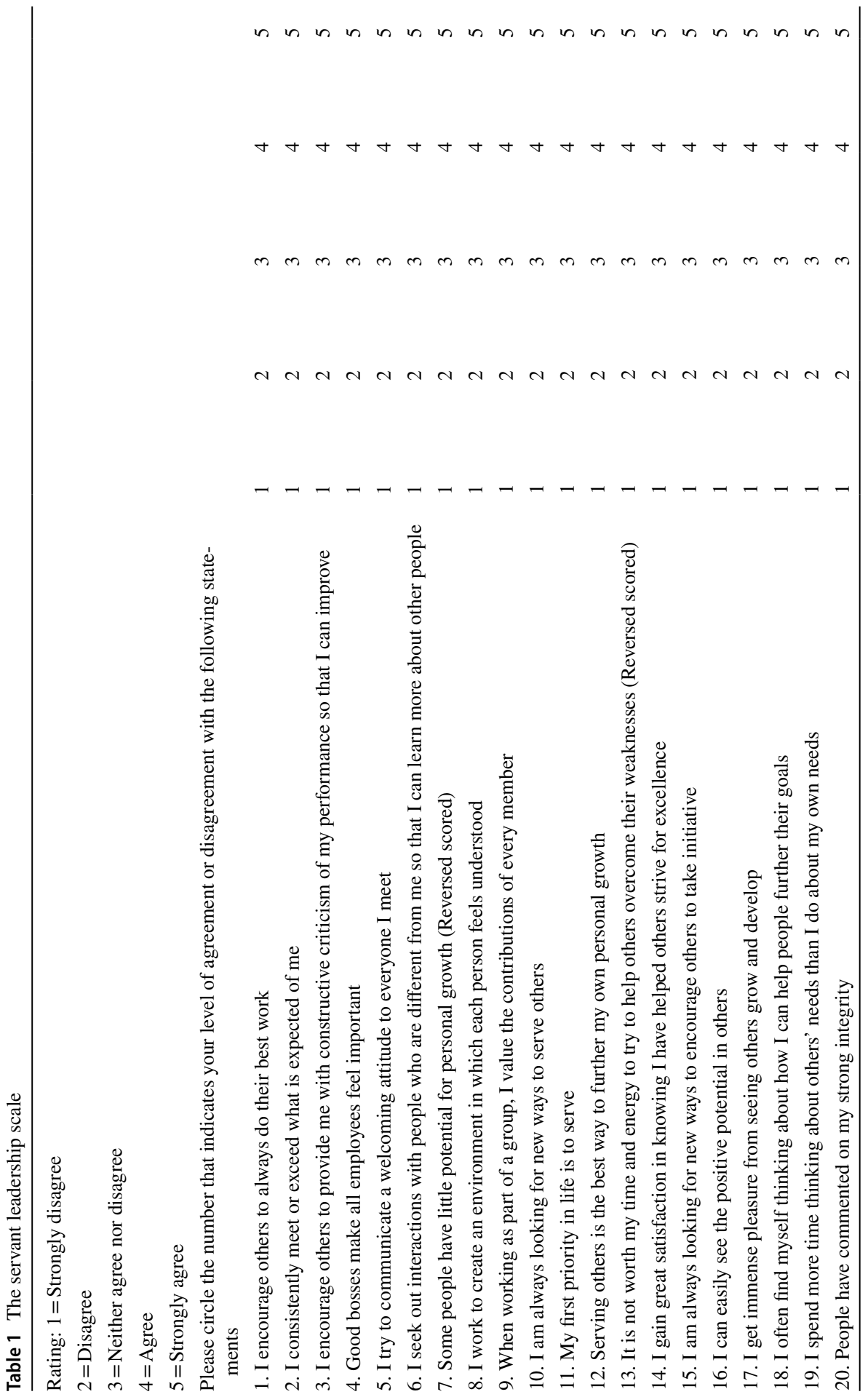




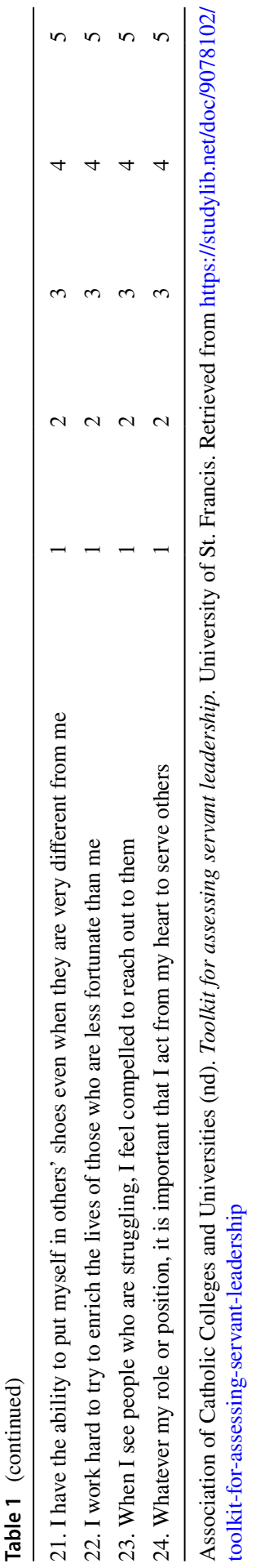


diversity and treating all people with dignity and respect; personal integrity is maintaining high ethical standards in one's life; and accountability is taking responsibility for one's actions (see Table 1). The Servant Leadership Scale available through public domain was developed by the ACCU (nd). This instrument utilizes a fivepoint Likert scale with responses ranging from strongly disagree to strongly agree. Possible total scores range from 24 to 120 with higher scores indicating increased servant leadership attributes. The scale has reported construct validity and an alpha coefficient of 0.93 (ACCU, nd). In this study Cronbach's alpha was 0.86 .

The Spirituality Scale measures spirituality as conceptually defined by Nelms et al. (2007) (see Table 2). Approval to use the Spirituality Scale was obtained from the author (L. Nelms, personal communication, February 17, 2020). The 13 items on the Spirituality Scale are rated on a five-point Likert scale from strongly disagree to strongly agree with higher scores indicating increased spirituality characteristics. The possible range of scores for the Spirituality Scale is 13 to 65 . The construct validity of the Spirituality Scale has been established and has a reported alpha coefficient of 0.95 (Nelms et al., 2007). In this study Cronbach's alpha was 0.97.

Table 2 The spirituality scale

Indicate the response that demonstrates how much you agree or disagree with each statement

1. Strongly disagree

2. Disagree

3. Neutral

4. Agree

5. Strongly agree

1. My spiritual beliefs help me to be a better person

2. My spirituality is at the core of who I am

3. My spirituality is my inner voice speaking to me

4. I believe God, Creator, or Higher Power is present in my life

5. My spiritual beliefs are the foundation for my religious background

6. My spiritual beliefs make my life more meaningful

7. I feel as if my life has a higher purpose

8. My spiritual beliefs positively impact my health and well-being

9. My spiritual beliefs guide my relationships with other people

10. I would feel lost without my spiritual beliefs directing my life

11. I am a very spiritual person

12. I try to be a spiritual person

13. My spirituality is a personal connection with God or a Higher Power

$\begin{array}{lllll}1 & 2 & 3 & 4 & 5 \\ 1 & 2 & 3 & 4 & 5 \\ 1 & 2 & 3 & 4 & 5 \\ 1 & 2 & 3 & 4 & 5 \\ 1 & 2 & 3 & 4 & 5 \\ 1 & 2 & 3 & 4 & 5 \\ 1 & 2 & 3 & 4 & 5 \\ 1 & 2 & 3 & 4 & 5 \\ 1 & 2 & 3 & 4 & 5 \\ 1 & 2 & 3 & 4 & 5 \\ 1 & 2 & 3 & 4 & 5 \\ 1 & 2 & 3 & 4 & 5 \\ 1 & 2 & 3 & 4 & 5\end{array}$

Nelms, L. W., Hutchins, E., Hutchis, D. \& Pursley, R.J. (2007). Spirituality and the health of college students. Journal of Religion and Health, 46(2), 249-265 


\section{Data Analysis}

The necessary sample size with a significance level of $\alpha=0.05$ and power $=0.80$ for a medium effect size is 64 (Faul et al., 2007). The statistical software program Statistical Package for Social Sciences (SPSS) version 26 was used to analyze the data. Descriptive statistics were used to describe student characteristics. Inferential statistics including Pearson product moment coefficients and analysis of variance were used to analyze the servant leadership and spirituality characteristics of undergraduate and graduate nursing students and to determine the relationships among demographic characteristics, servant leadership and spirituality.

\section{Results}

\section{Sample Characteristics}

Eighty-one students submitted surveys; exclusions of surveys with missing information resulted in 66 completed surveys from students enrolled in a pre-licensure Bachelor of Science in Nursing (BSN) $(N=29,43.9 \%)$ in Master of Science in Nursing (MSN) programs, which included both the Clinical Nurse Leader (CNL) program and the Nurse Practitioner (NP) program $(N=29,43.9 \%)$, and doctoral programs (either Doctor of Philosophy or Doctor of Nursing Practice $(N=7,10.6 \%)$. Of the 66 surveys, one student omitted only the type of program item and other data was therefore included in the analysis.

Demographic data of the students are shown in Table 3. The mean age of students was 28.81 years $(\mathrm{SD}=10.77)$. Consistent with the current workforce, the sample consisted of predominantly females $(N=55,83 \%)$ as compared to males. The results demonstrated that $31.8 \%(N=21)$ had no prior employment in healthcare and $19.7 \%(N=13)$ had more than 10 years of healthcare employment. Most students $(N=35,53 \%)$ had participated in volunteer services within the past 3 years beyond that required by an academic program.

\section{Servant Leadership Characteristics}

The mean score of servant leadership characteristics was 101.85 (SD=8.92) with the possible range of 24-120 indicating relatively high servant leadership scores. As shown in Table 4, servant leadership was not significantly correlated with any demographic variables. Servant leadership demonstrated a moderate, positive statistically significant correlation with spirituality $(r=0.42, p<0.001)$. Among the eight servant leadership subscales, the highest score was observed in the empowering others subscale $(M=24.07, \mathrm{SD}=3.10)$ and the lowest score was in the humility measurement $(M=3.65, \mathrm{SD}=1.15)$. Correlations between the eight servant leadership dimensions and spirituality are in Table 5. 
Table 3 Demographic characteristics $(N=66)$
Table 4 Correlations among demographic data, servant leadership, and spirituality

\begin{tabular}{|c|c|c|}
\hline Characteristic & $n$ & Percent $(\%)$ \\
\hline \multicolumn{3}{|l|}{ Gender } \\
\hline Male & 11 & 16.7 \\
\hline Female & 55 & 83.3 \\
\hline \multicolumn{3}{|l|}{ Ethnicity } \\
\hline White & 38 & 57.6 \\
\hline Black or African American & 4 & 6.1 \\
\hline Hispanic or Latino & 6 & 9.1 \\
\hline Asian Pacific Islander & 15 & 22.7 \\
\hline Other & 2 & 3 \\
\hline Missing & 1 & \\
\hline \multicolumn{3}{|l|}{ Degree program } \\
\hline BSN (Bachelor of Science in Nursing) & 29 & 43.9 \\
\hline CNL (Clinical Nurse Leader) & 6 & 9.1 \\
\hline NP (Nurse Practitioner) & 23 & 34.8 \\
\hline $\begin{array}{l}\mathrm{PhD} \text { or DNP (Doctor of Philosophy or } \\
\text { Doctor of Nursing Practice) }\end{array}$ & 7 & 10.6 \\
\hline Missing & 1 & \\
\hline \multicolumn{3}{|l|}{ Years employed in healthcare } \\
\hline None & 21 & 31.8 \\
\hline $1-3$ & 14 & 21.2 \\
\hline $4-6$ & 7 & 10.6 \\
\hline $7-10$ & 11 & 16.7 \\
\hline More than 10 & 13 & 19.7 \\
\hline \multicolumn{3}{|l|}{ Volunteer participation } \\
\hline Yes & 35 & 53.0 \\
\hline No & 31 & 47.0 \\
\hline
\end{tabular}

\begin{tabular}{lll}
\hline Demographic data & Servant leadership & Spirituality \\
\hline Age $^{1}$ & .130 & $.245^{*}$ \\
Gender $^{2}$ & -.022 & .049 \\
Ethnicity $^{3}$ & .042 & $.295^{* *}$ \\
Degree program $^{3}$ & .174 & $.230^{* * *}$ \\
Years employed in healthcare $^{2}$ & .194 & $.214 * * * *$ \\
Voluntary participation $^{2}$ & -.058 & -.164 \\
\hline${ }^{1} N=58,{ }^{2} N=66,{ }^{3} N=65, * p=.033, * * p=.009$, & $* * * p=.034$, \\
$* * * * p=.043$ & &
\end{tabular}

\section{Servant Leadership and Type of Nursing Program}

Analysis of variance revealed no statistically significant differences among the degree programs of $\mathrm{BSN}, \mathrm{MSN}$, and doctoral programs in characteristics of servant leadership. However, a trend was apparent in that BSN students had lower scores 
Table 5 Correlations between servant leadership, servant leadership subscales, and spirituality
Table 6 Means and standard deviations of communication subscale (by type of program)

Table 7 Analysis of variance: servant leadership communication subscale by type of program

\begin{tabular}{ll}
\hline Servant leadership & Spirituality \\
\hline Servant leadership total $^{1}$ & $.419^{*}$ \\
Subscale: accountability $^{2}$ & .185 \\
Subscale: cultural leadership $^{3}$ & $.208^{* *}$ \\
Subscale: communication $^{3}$ & .113 \\
Subscale: stewardship $^{1}$ & $.324^{* *}$ \\
Subscale: empowering others $^{3}$ & $.355^{* *}$ \\
Subscale: humility $^{2}$ & $.218^{* *}$ \\
Subscale: personal integrity $^{3}$ & $.319^{* *}$ \\
Subscale: social justice $^{3}$ & $.324^{*}$ \\
\hline
\end{tabular}

${ }^{1} N=62,{ }^{2} N=65,{ }^{3} N=64, * p<.001, * * p=.05$

\begin{tabular}{llll}
\hline Type of program & $n$ & Mean & $\begin{array}{l}\text { Standard } \\
\text { devia- } \\
\text { tion }\end{array}$ \\
\hline Traditional BSN & 29 & 9.27 & .921 \\
CNL & 6 & 9.83 & .408 \\
NP & 23 & 9.65 & .647 \\
DNP or PhD & 6 & 8.83 & .752 \\
\hline
\end{tabular}

$N=64$

\begin{tabular}{lcllll}
\hline Communication & Sum of squares & $d f$ & Mean square & $F$ & $p$ \\
\hline Between groups & 4.92 & 3 & 1.64 & 2.690 & .05 \\
Within groups & 36.67 & 60 & .61 & & \\
Total & 41.60 & 63 & & & \\
\hline
\end{tabular}

$N=63$

$(M=99.71, \mathrm{SD}=8.86)$ than those in the MSN programs $(M=104.33, \mathrm{SD}=8.62)$, after which servant leadership scores slightly declined for doctoral students $(M=101.42, \mathrm{SD}=9.18)$. Although BSN scores were lower than MSN scores, overall they were still relatively high servant leadership scores.

Of the servant leadership subscales, communication and the type of nursing program demonstrated a statistically significant relationship $(r=0.351, p=0.05)$. Those enrolled in the traditional BSN program or one of the MSN programs had higher scores on the communication dimension than those students enrolled in a doctoral program (see Table 6). A one-way ANOVA revealed statistically significant differences in communication by program type with doctoral students scores yielding the lowest means scores (see Table 7). 


\section{Servant Leadership and Years Employed in Healthcare}

Students without any previous healthcare employment demonstrated relatively high servant leadership scores $(M=100.42, \mathrm{SD}=7.41)$ were mostly BSN students $(n=20)$. In students that were employed in healthcare scores increased over time up to 10 years ( $1-3$ years $M=99.61, S D=10.03$; 4-6 years $M=101.16$, $\mathrm{SD}=8.88$; 7-10 years $\mathrm{M}=106.60, \mathrm{SD}=9.62$ ) and then declined (more than 10 years $\mathrm{M}=103.07, \mathrm{SD}=9.39)$. All students with more than 10 years of healthcare employment were either MSN $(n=5)$, or doctoral students $(n=7)$.

\section{Spirituality Characteristics}

Students' spirituality revealed a mean score of $51.10(\mathrm{SD}=13.7)$. Spirituality demonstrated significant but albeit weak correlations with age $(r=0.25, p<0.05)$, program degree $(r=0.23, p<0.05)$, and years employed in healthcare $(r=0.21, p<0.05)$. These findings indicate that older students enrolled in graduate programs and working longer in healthcare demonstrated higher levels of spirituality than younger students enrolled in baccalaureate programs with fewer years employed in healthcare. Although a correlation between ethnicity and spirituality was noted, further analysis of variance revealed no statistically significant differences between ethnicity and spirituality.

As for the responses concerning spirituality, the belief in the presence in their life of God, Creator, or Higher Power had the highest mean scores $(M=4.27, \mathrm{SD}=0.953)$ and was closely followed by the students' belief that their life has a higher purpose $(M=4.26, \mathrm{SD}=0.997)$. Most students indicated trying to be a spiritual person $(N=50$, $75.8 \%)$; however, fewer students acknowledged being a very spiritual person $(N=38$, $57.6 \%)$.

\section{Spirituality and Type of Nursing Program}

Spirituality scores increased as students pursued higher degrees, with BSN students having lower mean scores for spirituality $(M=48.25, \mathrm{SD}=14.74)$ and incrementally increasing with doctoral students demonstrating the highest spirituality scores $(M=57.00, \mathrm{SD}=9.38)$.

\section{Spirituality and Years Employed in Healthcare}

Spirituality scores for students that were never employed in healthcare were high $(M=50.23, \mathrm{SD}=13.03)$ and then initially declined as students entered the workforce (1-3 years, $M=44.69, \mathrm{SD}=17.48$ ). As students accumulated more years of experience their spirituality scores continued to increase (4-6 years, $M=50.57, \mathrm{SD}=12.24$; $7-10$ years, $M=54.54, \mathrm{SD}=12.25$; more than 10 years, $M=56.30, \mathrm{SD}=11.32$ ). 


\section{Servant Leadership and Spirituality}

Table 5 demonstrates the association between the subscales of servant leadership and spirituality. Of the 8 dimensions of servant leadership, except for accountability and communication, all subscales have weak to moderate statistically significant correlations with spirituality.

\section{Discussion}

There exists a dearth of literature on the characteristics of servant leadership and spirituality among nursing students. This study described these characteristics, factors influencing these behaviors, and the relationship between servant leadership and spirituality in undergraduate and graduate students enrolled in a nursing program at a faith-based institution.

Both the Servant Leadership Scale and the Spirituality Scale each possess sound psychometric properties and are notable because both were developed for use in samples of college age populations. To the best of our knowledge, the use of the Servant Leadership Scale was not found in any previously published research studies. Both instruments demonstrated strong psychometric properties in this research which expands and supports the use of these instruments to measure servant leadership and spirituality.

This sample of pre-licensure and licensed registered nurses demonstrated high levels of both servant leadership and spirituality characteristics. As nursing is a caring profession, nursing students, as demonstrated in this study, may inherently possess characteristics of servant leadership and spirituality. Additionally, perhaps these characteristics are further developed within clinical experiences with supportive mentors. Students who enter the nursing profession do so with a vision of caring to serve others and intentions to do good (Collins et al., 2019). These altruistic intentions may account for these students self-selecting the nursing profession as a career choice. This may be especially true for these students as this study was conducted in a faith-based university. The results may differ for students in universities that are not faith-based.

Although not statistically significantly different, students in all nursing programs possessed positive servant leadership characteristics, revealing an increasing trend from the BSN through the MSN programs, but then decreased among doctoral students. One subscale, communication which refers to valuing the contributions of group members and creating an environment where each person feels understood demonstrated a lower mean score among doctoral students than other students (see Table 6). This finding was statistically significant (see Table 7). A possible explanation for this finding pertains to doctoral education, whereby when doctoral students engage in scholarly pursuits and exploration of philosophical inquiry, independent thought processes are valued. Thus, they may no longer seek, desire, or engage in group membership to the same extent that a baccalaureate or MSN student does.

The results also revealed that increased experience in healthcare demonstrated increasing servant leadership scores. However, after practicing in healthcare greater 
than ten years there was a decline in servant leadership scores. Consistent with existing research, a possible explanation for this decline could be that with more years of experience nurses begin to minimize the needs of others, essentially experiencing burnout characterized as a loss of idealism, lack of engagement, or detached concern (Odonkor \& Frimpong, 2020). Similarly, Herman et al. (2017) reported a reduction in interaction effectiveness of nurse leaders when the age between leader and follower increases. Another possibility is that the doctoral students, typically older than BSN and MSN students, may be leaders in their nursing careers and have adopted by choice or institutional influence leadership styles other than servant leadership (Collins et al., 2019; Herman et al., 2017).

Spirituality was evident in these nursing students by means of their belief in a higher power, feeling that their life has a greater purpose and that spiritual beliefs positively impact their health and well-being. The findings of this study also revealed that students upon entering a nursing program have well developed spirituality characteristics that decline slightly in their early years in healthcare but then rebound and continue to develop over their professional nursing careers. As nurses become more accustomed to their challenging roles in care delivery to the most vulnerable patients, self-awareness enables nurses to derive deep meaning and real purpose in their lives, thus sustaining their spirituality.

The need for spiritual care delivery to patients dealing with the spiritual emergencies and rapidly deteriorating health without the presence of their loved ones has been amplified by the catastrophic mortality of the coronavirus disease (COVID19). Given the highly stressful nature of this disease, in order to provide holistic care and substitute as surrogate family members for near death patients, nurses' spirituality remains absolutely critical to offset the emotional distress encountered by this magnitude of loss.

Students enter nursing programs with the hope of academic and future success as caring health professionals. Faith-based university settings facilitate the development and expansion of spirituality and servant leadership among nursing students. Overall, this study revealed an association between spirituality and servant leadership. This is especially true of certain aspects of servant leadership such as empowering others. The spirituality of student participants was reflected in their ability to serve others, help others grow, develop, further their goals, and strive for excellence. This finding supports Robinson's (2015) study of graduate nurses' experiences that found spirituality was associated with professional and personal empowerment when they provide care to others.

\section{Limitations}

The findings of this study offer important possibilities for future research; however, the results should be interpreted within the context of several limitations. The study participants $(\mathrm{N}=66)$ were limited to a small convenience sample of undergraduate and graduate nursing students at one faith-based university that self-selected to participate. The relatively small sample size of students, especially that of doctoral students, limits the generalizability of the findings. The self-selection process may have 
posed a threat to the internal validity of the study as it is possible that only those undergraduate and graduate students with an interest in servant leadership and spirituality responded to the survey. While these findings are likely applicable to similar universities, individuals with inherent servant leadership and spirituality characteristics may be attracted to a faith-based university with a mission addressing servant leadership and spirituality (Astle \& Gibson, 2017).

\section{Conclusion}

This study was conducted to address the limited understanding of servant leadership and spirituality in the academic environment. Although the nursing profession is commonly perceived as a career with secure employment and financial rewards, this study demonstrates that undergraduate and graduate nursing students possess the characteristics of servant leadership and spirituality. This research contributes to further understanding of the value of servant leadership and spirituality in nursing and suggests there may be an inherent possession of these characteristics that may foster the selection of nursing as a career.

\section{Implications}

Nurse leaders as educators and administrators need to impart the value of servant leadership and spirituality characteristics to nursing students, future nurse leaders. The findings of this research may be of value to nurse educators as they develop curriculum and expand content of these important characteristics, and nurse leaders as they develop policies and workplace programs. While this study contributed to the body of knowledge on servant leadership and spirituality among nursing students further research is indicated. Additional research should include investigating these characteristics among nursing students in academic institutions other than faithbased universities. Recognizing servant leadership as the most fitting leadership style for nursing, nurse leaders need to nurture and support servant leadership to retain compassionate nurses in the workforce. Further attention devoted to the philosophical, conceptual, and methodological inquiry will expand and contribute to the existing knowledge of servant leadership and spirituality in nursing. Given the rising incidence of vulnerable, disadvantaged, and startling health care inequities among populations, servant leadership and spirituality among health professionals assumes even greater importance to deliver compassionate care.

Author's Contributions All authors contributed to the study conception and design. Material preparation, data collection and analysis were performed by both authors. The first draft of the manuscript was written by Joyce L. Maglione and both authors commented on previous versions of the manuscript. Both authors read and approved the final manuscript.

Funding No funding was received to assist with the preparation of this manuscript. 


\section{Declarations}

Conflict of interest The authors report no conflict of interest.

\section{References}

Almazon, J. U., Cruz, J. P., Alamri, M. S., Alotaibi, J. S. M., Albougami, A. S. B., Gravoso, R., Abocejo, F., Allen, K., \& Bishwajit, G. (2018). Predicting patterns of disaster-related resiliency among older adult Typhoon Haiyan survivors. Geriatric Nursing, 39(6), 629-634.

Ashmos, D., \& Duchon, D. (2000). Spirituality at work. Journal of Management Inquiry, 9(2), 134-145.

American Holistic Nurses Association. (2020). Where we come from. https://www.ahna.org/About-Us/ Where-We-Come-From.

Association of Catholic Colleges and Universities. (n.d.). Toolkit for assessing servant leadership. University of St. Francis. https://studylib.net/doc/9078102/toolkit-for-assessing-servant-leadership.

Astle, B., \& Gibson, D. (2017). Finding our place: Making the connection toward faith integration. Journal of Christian Nursing, 34(2), 108-111.

Baykal, E., Zehir, C., \& Kole, M. (2018). Effects of servant leadership on gratitude, empowerment, innovativeness, and performance: Turkey example. Journal of Economy, Culture, and Society, 57, 29-52.

Coetzer, M. F., Bussin, M., \& Geldenhuys, M. (2017). The functions of a servant leader. Administrative Sciences, 7(1), 5. https://doi.org/10.3390/admsci7010005

Collins, E., Owen, P., Digan, J., \& Dunn, F. (2019). Applying transformational leadership in nursing practice. Nursing Standard, 35(5), 59-65. https://doi.org/10.7748/ns.2019.e11408

DeConinck, B., Hawkins, L. A., Fyke, J. P., Neal, T., \& Currier, K. (2016). Spiritual care practices of advanced practice nurses: A multinational study. Journal for Nurse Practitioners, 12(8), 536-544.

Farrington, S. M., \& Lillah, R. (2018). Servant leadership and job satisfaction within private healthcare practices. Leadership in Health Services, 32(1), 148-168.

Faul, F., Erdfelder, E., Lang, A. G., \& Buchner, A. (2007). G*Power 3: A flexible statistical power analysis program for the social, behavioral, and biomedical sciences. Behavior Research Methods, 39, 175-191.

Focht, A., \& Ponton, M. (2015). Identifying primary characteristics of servant leadership: Delphi study. International Journal of Leadership Studies, 9(1), 44-61.

Greenleaf, R. K. (2002). Servant leadership: A journey into the nature of legitimate power and greatness (25th anniversary ed.). Paulist Press.

Herman, S., Gish, M., Rosenblum, R., \& Herman, M. (2017). Effects of RN age and experience on transformational leadership practices. Journal of Nursing Administration, 46(6), 327-337.

Hesse, H. (2003). The journey to the east (H. Rosner, Trans.). Picador. (Original work published 1932)

Hospice \& Palliative Nurses Association. (2015). Spiritual care (Position statement). https://advancinge xpertcare.org/position-statements/

Jafai, M., Moghadam, E., \& Hosseini, S. M. (2016). The relationship between servant leadership style and work engagement with managers' efficiency in Zahedan Medical Services University Hospitals. International Journal of Humanities and Culture Studies, 5(2016), 1835-1847.

Khan, S. E., Khan, K. E., \& Chaudhry, A. J. (2015). Impact of servant leadership on workplace spirituality: Moderating role of involvement culture. Pakistan Journal of Science, 67(1), 109-113.

Liden, C., Wayne, J., Zhao, H., \& Henderson, H. (2008). Servant leadership: Development of a multidimensional measure and multi-level assessment. The Leadership Quarterly, 19(2), 161-177.

Masters, K. (2015). Nursing theories: A framework for professional practice (2nd ed.) Jones \& Bartlett Learning.

Naseer, S., Syed, F., Nauman, S., Fatima, T., Jameel, I., \& Riaz, N. (2020). Understanding how leaders' humility promotes followers' emotions and ethical behaviors: Workplace spirituality as a mediator. Journal of Positive Psychology, 15(3), 407-419. https://doi.org/10.1080/17439760.2019.1615103

Nelms, L. W., Hutchins, E., Hutchis, D., \& Pursley, R. J. (2007). Spirituality and the health of college students. Journal of Religion and Health, 46(2), 249-265.

Nightingale, F. (1860). Notes on nursing: What it is and what it is not. D. Appleton and Company. 
O'Brien, M. E. (2014). Spirituality in nursing: Standing on holy ground (5th ed.). Jones \& Bartlett Learning.

Odonkor, S. T., \& Frimpong, K. (2020). Burnout among healthcare professionals in Ghana: A critical assessment. Biomed Research International. https://doi.org/10.1155/2020/1614968

Ozawa, C., Suzuki, T., Mizuno, Y., Tarumi, R., Yoshida, K., Fujii, K., Hirano, J., Tani, H., Rubinstein, E. B., Mimura, M., \& Uchida, H. (2017). Resilience and spirituality in patients with depression and their family members: A cross-sectional study. Comprehensive Psychiatry, 77, 53-59. https://doi. org/10.1016/j.comppsych.2017.06.002

Rahmati, A., Sajjadi, M., \& Negarestani, A. (2018). A spiritual approach to job satisfaction and motivation among special education teachers. Health, Spirituality and Medical Ethics Journal, 5(3), 29-35. https://doi.org/10.29252/jhsme.5.3.29

Reddy, A. V. (2019). Servant leadership and spirituality at workplace: A critical review. International Journal on Leadership, 7(1), 8-12.

Robinson, I. (2015). Spiritualty: The meaning as experienced by nurses enrolled in a graduate nursing program. International Journal of Nursing Education, 7(3), 56-60.

Roming, S., \& Howard, K. (2019). Coping with stress in college: An examination of spirituality, social support, and quality of life. Mental Health, Religion and Culture, 22(8), 832-843. https://doi.org/10. 1080/1367467.2019.1674794

Schwarz, G., Newman, A., Cooper, B., \& Eva, N. (2016). Servant leadership and follower job performance: The mediating effect of public service motivation. Public Administration, 94(4), 1025-1041. https://doi.org/10.1111/padm.12266

Sheikh, A. A., Ishaq, Q., \& Inam, A. (2019). Fostering creativity through servant leadership: Mediating role of knowledge sharing, thriving at work and burnout. Abasyn Journal of Social Sciences, 12(2), 198-212.

Sipe, J. W., \& Frick, D. M. (2009). Seven Pillars of Servant Leadership: Practicing the Wisdom of Leading by Serving. Paulist Press.

Spears, L. C. (2010). Character and servant leadership: Ten characteristics of effective, caring leaders. The Journal of Virtues and Leadership, 1(1), 25-30.

Wu, X., Hayter, M., Lee, A. J., Yuan, Y., Li, S., Bi, Y., Zhang, L., Cao, Cl., Gong, W., \& Zhang, Y. (2020). Positive spiritual climate supports transformational leadership as a means to reduce nursing burnout and intent to leave. Journal of Nursing Management, 28(4), 804-813. https://doi.org/10. 1111/jonm.12994

Publisher's Note Springer Nature remains neutral with regard to jurisdictional claims in published maps and institutional affiliations. 